\title{
Optimal Design of Passive Flow Control for a Boundary- Layer-Ingesting Offset Inlet Using Design-of-Experiments
}

\author{
Brian G. Allan*, Lewis R. Owens ${ }^{\dagger}$, and John C. Lin* \\ NASA Langley Research Center, Hampton, VA, 23681
}

\begin{abstract}
This research will investigate the use of Design-of-Experiments (DOE) in the development of an optimal passive flow control vane design for a boundary-layer-ingesting (BLI) offset inlet in transonic flow. This inlet flow control is designed to minimize the engine fan-face distortion levels and first five Fourier harmonic half amplitudes while maximizing the inlet pressure recovery. Numerical simulations of the BLI inlet are computed using the Reynolds-averaged Navier-Stokes (RANS) flow solver, OVERFLOW, developed at NASA. These simulations are used to generate the numerical experiments for the DOE response surface model. In this investigation, two DOE optimizations were performed using a DOptimal Response Surface model. The first DOE optimization was performed using four design factors which were vane height and angles-of-attack for two groups of vanes. One group of vanes was placed at the bottom of the inlet and a second group symmetrically on the sides. The DOE design was performed for a BLI inlet with a free-stream Mach number of 0.85 and a Reynolds number of 2 million, based on the length of the fan-face diameter, matching an experimental wind tunnel BLI inlet test. The first DOE optimization required a fifth order model having 173 numerical simulation experiments and was able to reduce the DC60 baseline distortion from $64 \%$ down to $4.4 \%$, while holding the pressure recovery constant. A second DOE optimization was performed holding the vanes heights at a constant value from the first DOE optimization with the two vane angles-of-attack as design factors. This DOE only required a second order model fit with 15 numerical simulation experiments and reduced DC60 to $3.5 \%$ with small decreases in the fourth and fifth harmonic amplitudes. The second optimal vane design was tested at the NASA Langley 0.3Meter Transonic Cryogenic Tunnel in a BLI inlet experiment. The experimental results showed a $80 \%$ reduction of $\mathrm{DPCP}_{\mathrm{avg}}$, the circumferential distortion level at the engine fanface.
\end{abstract}

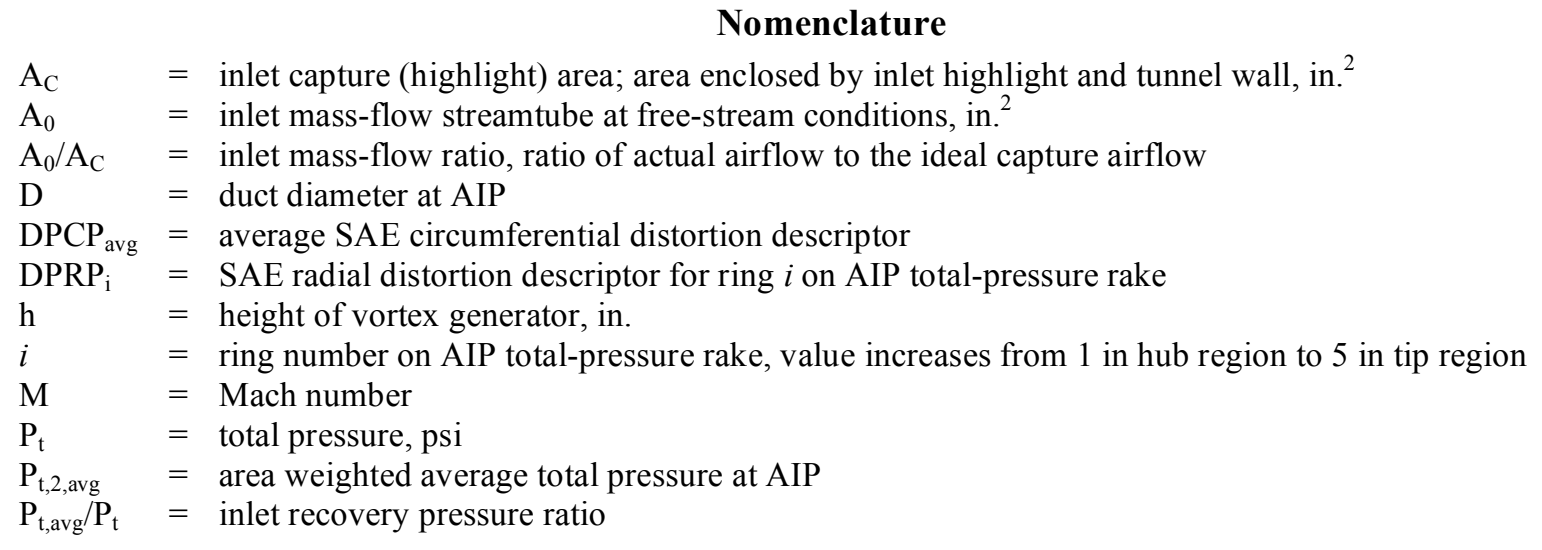

\footnotetext{
* Research Scientist, Flow Physics and Control Branch, MS 170, NASA Langley Research Center, Hampton, VA 23681, AIAA Senior Member.

${ }^{\dagger}$ Research Engineer, Flow Physics and Control Branch, MS 170, NASA Langley Research Center, Hampton, VA 23681, AIAA Senior Member.

$\$$ Senior Research Engineer, Flow Physics and Control Branch, MS 170, NASA Langley Research Center, Hampton, VA 23681, AIAA Associate Fellow.
} 


$$
\begin{array}{ll}
\mathrm{Re}_{\mathrm{D}} \quad= & \text { Reynolds number based on duct AIP diameter } \\
\mathrm{T}_{\mathrm{t}} \quad= & \text { total temperature, }{ }^{\circ} \mathrm{R} \\
\text { Subscripts: } & \\
\infty & =\text { free-stream conditions }
\end{array}
$$

Abbreviations:

$\begin{array}{ll}\text { AFC } & \text { active flow control } \\ \text { AIP } & \text { aerodynamic interface plane } \\ \text { BLI } & \text { boundary-layer ingesting } \\ \text { BWB } & \text { blended-wing-body } \\ \text { CFD } & \text { computational fluid dynamics } \\ \text { DOE } & \text { design of experiments } \\ \text { NASA } & \text { National Aeronautics and Space Administration } \\ \text { SAE } & \text { Society of Automotive Engineers } \\ \text { UEET } & \text { Ultra Efficient Engine Technology } \\ \text { VG } & \text { vortex generator }\end{array}$

\section{Introduction}

$\mathrm{N}$ an effort to reduce the environmental impact of commercial aircraft using revolutionary propulsion technologies, NASA initiated the Ultra Efficient Engine Technology (UEET) program ${ }^{1}$. One of the elements of the UEET program is the application of flush-mounted, boundary-layer-ingesting (BLI), offset (S-shaped) inlets on the aft portion of an aircraft as shown in Fig. 1. System studies for the Blended Wing Body (BWB) transport have shown significant reductions in fuel burn by using this type of inlet configuration ${ }^{2}$. For the BWB vehicle, a BLI inlet placed on the upper rear surface of the wing would have a 30\% boundary layer to inlet height ratio. The ingestion of such a large boundary layer, coupled with the S-shaped offset of the inlet diffuser, results in a large flow distortion at the engine fan-face $\mathrm{e}^{3-5}$. Figure 2 shows the numerical results for the baseline BLI inlet flow at the aerodynamic interface plane (AIP). This contour plot of the total pressure ratio at the AIP shows how the secondary flow generated by the S-shaped duct pools the boundary layer flow at the bottom of the AIP creating a large inlet flow distortion. Experiments and numerical simulations have shown that this inlet flow distortion can be improved to acceptable levels using flow control devices located inside the inlet ${ }^{4-6}$.

The application of flow control devices for inlets has been investigated since the late 1940s when Taylor ${ }^{7}$ used vortex generator (VG) vanes to re-energize the boundary layer to prevent flow separation. Inlet flow control research continued into the 1950 s by Grose and Taylor $^{8}$, Valentine and Carrol ${ }^{9,10}$, and Pearcy and Stuart ${ }^{11}$. The early design strategies used here were based on preventing flow separation within the inlet duct and were based on twodimensional boundary layer concepts. As a result of this design approach, the VG vanes did not perform well for inlets with regions of large secondary flows.

In 1973, Kaldschmidt, Syltebo, and Ting ${ }^{12}$ demonstrated that one could restructure the development of the secondary flow, improving engine face distortion. This work marked a shift in inlet flow control design, moving away from separation control to a global manipulation of the secondary inlet flow. This new design approach would require inlet flow control designs to solve the three-dimensional viscous flow equations. The paper by Anderson and Levy ${ }^{13}$ demonstrated how passive flow control devices could be designed by solving the three-dimensional reduced Navier-Stokes equations. Today inlet flow control designs are using Design of Experiments (DOE) to build a response surface model using design factors and optimizing the flow control design which minimizes flow distortion and high cycle fatigue while maximizing pressure recovery, all over a desired range of operating flow conditions for compact S-shaped inlet diffusers ${ }^{14-24}$.

While there has been significant research on inlet flow control, there has been very little research on flow control for inlets with large BLI. Anabtawi, Blackwelder, Liebeck, and Lissaman ${ }^{5}$ performed the first experiments using passive flow control for a BLI offset inlet at a very low Mach number. This experiment was able to demonstrate that passive vane devices could be used to improve the engine fan-face distortion to operational levels. Expanding on this research, Gorton, Owens, Jenkins, and Allan ${ }^{4}$ performed low Mach experiments on an S-shaped BLI inlet using active flow control jets and passive VG vanes. This experiment demonstrated that VG jets could be used to reduce the flow distortion. It also provided experimental data for the validation of OVERFLOW, a NASA developed Reynolds-averaged Navier-Stokes (RANS) flow solver ${ }^{6}$. Experimental data for the baseline BLI inlet in 
transonic flow was obtained by Berrier and Morehouse ${ }^{25}$ and was used to validate OVERFLOW for the baseline case $^{6}$. These validations of the flow solver provided confidence to use OVERFLOW for the design of flow control jets in the BLI inlet for an experiment at transonic Mach numbers ${ }^{26}$. The flow solver was used to identify candidate jet actuator locations that were built into the BLI inlet wind tunnel model. This research will use the experimental VG vane results from the wind tunnel data by Owens, Allan, and Gorton ${ }^{26}$. Validation of OVERFLOW for the BLI inlet flow control problem, was performed by Allan and Owens ${ }^{27}$.

This research will investigate the use of DOE in the optimization of passive flow control vanes for a BLI inlet at transonic Mach numbers. A DOE optimization approach was performed using a D-Optimal Response Surface method with four design factors. The factors were vane heights and angles of attack for two groups of vanes, one group on the bottom and one on each side of the inlet. The main advantages of a DOE approach are the ability to objectively identify the interaction of the design factors and main effects minimizing the uncertainty in the response coefficients using a compact test matrix ${ }^{28}$. An optimum vane configuration was found by minimizing the response variables of engine fan-face distortion, DC60, and the first five half amplitude fan-face harmonics while maximizing the pressure recovery. A second DOE of was performed using the results from the first DOE where the vane heights were fixed and the only design factors were the vane angles for the two groups of vanes on the bottom and sides of the inlet. The performances of the vanes were then evaluated in a BLI inlet experiment at NASA Langley's 0.3Meter Transonic Cryogenic Tunnel.

\section{Numerical Modeling Approach}

The steady-state flow field for the BLI offset inlet with VG vanes was computed using the flow solver code, OVERFLOW, developed at NASA ${ }^{29,30}$. This code solves the compressible RANS equations using the diagonal scheme of Pulliam and Chaussee ${ }^{31}$. The RANS equations are solved on structured grids using the overset grid framework of Steger, Dougherty, and Benek ${ }^{32}$. This overset grid framework allows for the use of structured grids for problems that have complex geometries. To improve the convergence of the steady-state solution, OVERFLOW also includes a low-Mach number preconditioning option and a multigrid acceleration routine. All of the simulations in this study used Menter's two-equations (k- $\omega$ ) Shear-Stress Transport (SST) turbulence model ${ }^{33}$. The SST turbulence model was found to be the best turbulence model option in OVERFLOW for the simulation of streamwise vortices embedded in a boundary layer ${ }^{34}$.

The numerical simulations were performed using the parallel version of the OVERFLOW code developed by Buning $^{35}$. This code uses the Message-Passing Interface (MPI) and can run on a tightly-coupled parallel machine or a network of workstations. The code distributes zones to individual processors and can split larger individual zones across multiple processors using a domain decomposition approach.

The structured overset grid system was generated using the Chimera Grid Tools package ${ }^{36}$. Figure 3 shows a close-up view of the overset grids near the VG vanes on the inlet surface. The vanes were modeled as rectangular fins, which was shown to be comparable to a fully modeled trapezoidal vane ${ }^{34}$. Each of the inlet simulations had 33 grids with a total of 11.4 million grid points and was solved in 2.5 hours using 56 CPU on an SGI 3700 Altix.

\section{Wind Tunnel Experiment}

The transonic BLI inlet experiments were conducted at NASA Langley's 0.3-Meter Transonic Cryogenic Tunnel (0.3-Meter Tunnel) for the BLI offset inlet described by Owens, Allan, and Gorton ${ }^{26}$. The experimental data was taken over a Mach number range of 0.78 to 0.87 with a Reynolds number range of $\operatorname{Re}_{\mathrm{D}}=2 \cdot 10^{6}$ to $4 \cdot 10^{6}$, where the engine fan-face or aerodynamic interface plane (AIP) diameter, $\mathrm{D}=2.448$ inches. This experiment was able to test the BLI inlet at the actual flight Mach numbers expected for the BWB aircraft application. This experiment generated a large boundary layer of approximately $35 \%$ of the inlet height ratio.

The VG vane design was performed using a free-stream Mach number of 0.784 since this was the expected maximum Mach number for the wind tunnel test. A previous baseline BLI inlet experiment in the 0.3-Meter Tunnel at high Reynolds number was only able to reached a maximum Mach number of 0.83 upstream of the adaptive flex wall system $^{25}$. The adaptive flex walls were not working for this test and were held open at a fix $0.4^{\circ}$ of divergence angle. This divergence angle resulted in a slowing down of the flow as it approached the inlet. Numerical simulations for the BLI inlet were shown to match a boundary rake velocity measurement on the outside of the inlet cowling aligned with the inlet highlight, for a free-stream Mach number of 0.784 where the tunnel had a Mach number of 0.83 upstream of the adaptive flex walls ${ }^{3}$. In addition a calculation of the local Mach number distribution on the wall opposite of the BLI inlet was made and is shown in Fig. 4. The local Mach number distribution in Fig. 4 was computed from pressure measurements on the wall centerline. The plot of the local Mach number distribution shows a linear decrease in the free-stream Mach number ahead of the inlet highlight, which is located at a tunnel 
station of -4.75 inches. Since then the adaptive flex wall system in the 0.3 -Meter Tunnel has been fixed, enabling the Mach number to reach 0.85 upstream of the BLI inlet ${ }^{26}$. Figure 4 shows how the walls were modified in order to maintain a constant free-stream Mach number of 0.85 upstream of the inlet. During the vane design it was not know if the free-stream Mach number would be able to reach 0.85 so the vane design was performed at an expected maximum Mach number of 0.784 .

The VG vane configuration used in the experiment is shown in Fig. 5. The vanes are located at a distance of $\mathrm{x} / \mathrm{D}=0.5$ inside of the inlet where $\mathrm{x}=0$ at the highlight of the inlet cowling. There were twelve vanes on the bottom and six on each side of the inlet for at total of 24 vanes. The side vanes had a height of $h / D=0.065$ and the bottom vanes had a height of $h / D=0.074$, approximately $30 \%$ of the boundary layer height ingested by the inlet. Both sets of vanes had chord lengths of $\mathrm{c} / \mathrm{D}=0.15$. The side vanes were positioned at an angle of 11.5 degrees to the freestream direction and the bottom vanes at 12.9 degrees.

The vanes were designed for an inlet mass flow ratio of $\mathrm{A}_{0} / \mathrm{A}_{\mathrm{C}}$ of 0.59 , where $\mathrm{A}_{\mathrm{C}}$ is the inlet capture area, enclosed by the cowling highlight and the free-stream mass flow rate for a given area $A_{0}$ is equal to the inlet mass flow rate. Therefore when $A_{0} / A_{C}$ is unity, the free-streamtube going into the inlet is not expanding or shrinking and when $A_{0} / A_{C}$ is less than one, the free-streamtube is expanding. Similarly, when $A_{0} / A_{C}$ is greater than one, the freestreamtube is shrinking as it approaches the inlet.

The inlet distortion and pressure recovery was measured using a 40-probe total pressure rake placed at the AIP location and was designed using the SAE standard ${ }^{37}$. This rake has eight arms spaced $45^{\circ}$ apart with five total pressure probes on each arm in the radial direction. The inlet distortion levels for the experiment were computed using the average SAE circumferential distortion descriptor, $\mathrm{DPCP}_{\text {avg, }}$ as defined in the SAE standard ${ }^{37}$. Unfortunately this rake was not able to compute a DC60 distortion value that was used in the optimization of the vane design. Comparison between the numerical and experimental results will be made using the $\mathrm{DPCP}_{\text {avg }}$ descriptor where the numerical results will be interpolated onto the 40-probe rake locations matching the experimental measurement resolution. This was done since the distortion levels were seen to vary slightly between 40 and 120 probes.

\section{Results}

\section{A. DOE Optimal Design}

An optimal VG vane design was performed using a DOE approach. Table 1 shows the four design factors, which are the vane height and angles-of-attack for a group of twelve vanes on the bottom of the inlet entrance and a second group of six vanes on the sides. The range of these design factors were chosen from previous experiences and performing a couple of evaluation simulations with VG vanes. Table 1 also lists a number of variables, which were held fixed such as the number of vanes in the bottom and side groups, vane chord length, free-stream Mach number, inlet mass flow rate, and the Reynolds number. One of the constraints on the vane design was that it be a single row of vanes inside the inlet. This constraint was included in order to reduce the complexity of the vane installation inside the inlet during the wind tunnel test. The number of vanes, chord length, and locations were determined from evaluation experiments and not included as part of the design factors. This was done since the vanes were being fully modeled inside the inlet making the numerical experiments very costly both in grid generation and computer resources. The vanes design was also made at a fixed Mach number and inlet mass flow rate in order to reduce the number of computational simulations and needed computer resources. The free-stream Mach number in the numerical simulations of the BLI inlet on a flat plate was held fixed at 0.784 . The inlet mass flow rate was also held fixed at $A_{0} / A_{C}$ of 0.55 , which was the highest mass flow rate achievable during the wind tunnel test of Berrier?

A D-optimal Response Surface DOE method was used where the order of the model was increased until a good response surface fit was found. Initially a second order model was generated using a block of 25 numerical experiments. The response surface model fit for the second order model was found to be very poor. The order of the model fit was increased to a third order model, requiring a second block of 32 numerical experiments. The model order was continually increased until a fifth order model was found to have a good fit. This fifth order model required a total of 173 numerical experiments.

Using the fifth order model, an optimal vane design was found by minimizing the DC60 distortion level and the first five Fourier harmonic half amplitudes, while maximizing the pressure recovery. The optimal design factors are given in Table 2 with the predicted and actual CFD response variables in Table 3. The D-Optimal response surface model predicted a DC60 value of $8.9 \%$ while a numerical simulation of the vane design resulted in a $4.5 \%$ DC60 distortion level. This is a significant improvement over the $64 \%$ baseline DC60 level where it's desirable to have a DC60 under $10 \%$. The actual distortion level calculated with CFD was better than the predicted distortion level 
from the Response Surface fit showing a significant difference in the predicted and actual distortion level. A contour plot of the total pressure ratio at the AIP for the numerical simulation of the vane design is shown in Fig. 5 . This contour plot shows how the vane design was able to manipulate the inlet secondary flow, distributing the low total pressure flow from the boundary layer.

It was noted that the optimal design from the first DOE evaluation produced a side vane angle of 10 degrees, which is on the edge of the DOE model space. This indicates that the optimum vane design may be located outside of this response surface model space. A second DOE optimization was performed in order to explore the region near the first optimization and to expand the side vane angle minimum boundary (see Table 4 for design factors ranges and response variables). In order to reduce the computational costs the vane heights were held fixed at the optimal values computed in the first DOE optimization while varying the vane angles. The computational cost was also reduced by decreasing the design space of the vane angles. The reduced order of the response surface model decreasing the number of CFD experiments. The DOE design factors for this second DOE evaluation are given in Table 4.

A good model fit was found using a second order D-Optimal DOE model requiring 15 numerical simulation experiments. The optimal vane angles, shown in Table 5, minimized DC60 and the harmonic amplitudes while maximizing the pressure recovery. In the optimization it was found that the angle-of-attack for the side vanes was 11.5 degrees, which was inside our first DOE optimization model space. Had the model fit in the first DOE been better this minimum point would have been found using the first DOE optimization. Table 6 shows a comparison of the predicted model response and a CFD simulation of the second optimal vane design, showing an improved model fit with much better agreement between the DOE predictions and the CFD calculations. This improved model fit is most likely due to the smaller model design space and the reduced number of design variables. A contour plot of the total pressure ratio at the engine fan-face for the second DOE optimization is shown in Fig. 7.

Figure 8 shows a summary of the actual DC60 levels for the CFD baseline simulation and the two DOE optimal vane designs. This figure shows how the second DOE optimization was able to slightly improve the DC60 distortion level over the first DOE optimization. Figure 9 shows a summary the actual harmonic amplitudes for the flow control DOE optimizations to the baseline case. This comparison shows that the first two harmonic levels were greatly reduced from the baseline case while also improving the other last three harmonic amplitudes in the second DOE vane design. The biggest difference between the two DOE optimizations is that the second DOE optimization was able to improve the fourth and fifth harmonic amplitudes. The first DOE optimization had the fourth and fifth harmonic slightly higher than the baseline.

\section{B. Experimental Results}

The vane design generated in the second DOE optimization were fabricated and tested in a BLI inlet experiment conducted at NASA Langley's 0.3-Meter Tunnel, accessing the design performance and the accuracy of the simulations ${ }^{26}$. Though the vanes were designed at a fixed $\mathrm{A}_{0} / \mathrm{A}_{\mathrm{C}}$ of 0.59 , they were evaluated over the full inlet mass flow range achievable in the wind tunnel test that ranged from a designed $\mathrm{A}_{0} / \mathrm{A}_{\mathrm{C}}$ range of 0.55 to 0.30 . Figure 10 shows a summary plot of the experimental results for the BLI inlet with and without vanes along with total pressure ratio contour plots at the AIP. This comparison shows that the VG vane design significantly improved the inlet $\mathrm{DPCP}_{\mathrm{avg}}$ distortion from the baseline value of 0.056 to 0.011 at $\mathrm{A}_{0} / \mathrm{A}_{\mathrm{C}}$ of 0.55 . The inlet mass flow sweep shows that the $V G$ vanes had a peak $\mathrm{DPCP}_{\mathrm{avg}}$ of 0.022 at an $\mathrm{A}_{0} / \mathrm{A}_{\mathrm{C}}$ of 0.46 which is below the acceptable static distortion level of 0.04 for commercial aircraft engines. Figure 10 shows the distortion levels for two different freestream Mach numbers since the vanes were designed at a $\mathrm{M}_{\infty}=0.78$ and the inlet was designed to operate at a cruise Mach number of 0.85. This comparison shows that the free-stream Mach number has a small effect on the inlet distortion for the baseline and VG vane flow control configuration. The AIP contour plots of the total pressure ratio show that the vanes were very effective in distributing the boundary layer flow evenly reducing the flow distortion from the baseline flow. As the inlet mass flow is decreased from $\mathrm{A}_{0} / \mathrm{A}_{\mathrm{C}}$ of 0.55 the boundary layer going into the inlet thickens creating a much larger BLI inlet problem. This is coupled with the fact that the flow is slowing down as $\mathrm{A}_{0} / \mathrm{A}_{\mathrm{C}}$ decreases and the slower flow reduces the control effectiveness of the vanes.

Figure 11 shows the total pressure recovery for the baseline and VG vanes that was fairly constant over the operating range of $\mathrm{A}_{0} / \mathrm{A}_{\mathrm{C}}$ from 0.45 to 0.55 . This comparison shows that the $\mathrm{VG}$ vanes produced a 0.005 decrease in the pressure recovery from the baseline case. Since the vanes are only redistributing the boundary layer flow and not reducing a flow separation, an increase in the pressure recovery would not be expected when using passive flow control devices such as VG vanes as work by extracting energy from the flow. It is speculated that the slight decrease in the pressure recovery could be related to a combination of the vanes extracting energy from the flow, flow separation on or near the vanes (i.e., device drag), and a total pressure measurement resolution at the AIP. While the vanes have decreased the circumferential distortion, $\mathrm{DPCP}_{\mathrm{avg}}$, they have also increased the radial 
distortion intensity, $\mathrm{DPRP}_{\mathrm{i}}$, on the outer two rings as shown in Fig. 12. The radial distortion intensity measures the difference between the face-average pressure and the ring-average pressure, divided by the face-average pressure where positive values reflect a ring average pressure that is below the face average. This comparison shows how the distribution of the boundary layer flow decreases the outer ring average pressures.

\section{Summary}

A DOE optimization approach was used to design passive flow control vanes inside a BLI offset inlet at transonic Mach numbers. This optimization focused on a single row of VG vanes at a constant streamwise station that was divided into two distinct groups. The first group had twelve vanes on the bottom of the inlet and the second group had a total of twelve vanes, six vanes on each side of the inlet. Since the vanes were to be installed in the BLI inlet during the test the design focused on a single row in an effort to reduce the complexity of the vane installation. These vanes were optimized using a DOE D-Optimal Response Surface method using four design factors. The design factors were vane height and angle-of-attack for each group of vanes. The free-stream Mach number and inlet mass flow rate were held at a fixed condition in an effort to reduce the number of numerical simulations and focus the vane design near the high inlet mass flow condition. The number of numerical simulations were greatly restricted by the fact the a fully grided vane approach required a large amount of computing resources. This required that the optimal design focus on the four vane design factors neglecting other design variables like vane chord length, number of vanes in each group and the streamwise vane location.

An optimum vane design was found by minimizing the response variables of engine fan-face distortion, DC60, and the first five Fourier harmonic half amplitudes, while maximizing the total pressure recovery. The first DOE used a D-Optimal model that required a fifth order model fit and 173 numerical simulations experiments. It was discovered that the optimal design was on the edge of the design space for the side vane angle-of-attack. A second DOE optimization was performed holding the vane heights constant and optimizing the two design factors of vane angle-of-attack for each group of vanes. The range of the design space for the vane angles-of-attack was also reduced decreasing response surface model order and the number of numerical experiments. The design space was also centered about the optimal side vane angle-of-attack in the first DOE optimization to see if the optimal point was out side the previous design space. The second DOE only required a second order model fit resulting in 15 numerical simulation experiments. This second DOE optimization had a much better fit and was able to improve the DC60 distortion levels and the fan-face harmonic amplitudes.

The optimal vane design was then used in a BLI inlet wind tunnel experiment at NASA Langley's 0.3-Meter Tunnel. The experimental results demonstrated a $80 \%$ decrease in $\mathrm{DPCP}_{\mathrm{avg}}$, the reduction in the circumferential distortion levels, at an inlet mass flow rate which as at the middle of the operational range at the cruise condition. While the vanes were designed at a single inlet mass flow rate, they performed very well over the entire inlet mass flow range tested in the wind tunnel experiment. While the circumferential distortion was decreased, the radial distortion on the outer rings at the AIP increased. This was a result of the large boundary layer being distributed from the bottom of the AIP in the baseline case to the outer edges of the AIP when using the VG vane flow control.

\section{Acknowledgments}

This research was supported by the NASA UEET Highly Integrated Inlet project office. The authors would like to thank Dr. Dick DeLoach for his assistance with the Design of Experiments part of this investigation. Special thanks to Mr. Bobby Berrier for his guidance on testing flush-mounted, boundary layer ingesting inlets. The authors would also like to thank Ms. Susan Gorton for her leadership and support during this research project. The authors would also like to thank Dr. Pieter Buning for his discussions and support of the numerical flow solutions.

\section{References}

${ }^{1}$ Brown, A. S., "HSR Work Propels UEET Program (High Speed Research in Ultraefficient Engine Technology in Aircraft Industry)," Aerospace America, Vol. 37, No. 5, May 1999, pp. 48-50.

${ }^{2}$ Liebeck, R. H., "Design of the Blended-Wing-Body Subsonic Transport,” AIAA 2002-002.

${ }^{3}$ Berrier, B. L. and Allan, B. G., "Experimental and Computational Evaluation of Flush-Mounted, S-Duct Inlets," AIAA Paper 04-0764, January 2004.

${ }^{4}$ Gorton, S. A., Owens, L. R., Jenkins, L. N., Allan, B. G., and Schuster, E. P., “Active Flow Control on a Boundary-LayerIngesting Inlet," AIAA Paper 04-1203, January 2004.

${ }^{5}$ Anabtawi, A. J., Blackwelder, R. F., Lissaman, P. B. S., and Liebeck, R. H., "An Experimental Investigation of Boundary Layer Ingestion in a Diffusing S-Duct With and Without Passive Flow Control," AIAA Paper 99-0739.

${ }^{6}$ Allan, B. G., Owens, L. R., and Berrier, B. L., "Numerical Modeling of Active Flow Control in a Boundary Layer Ingesting Offset Inlet," AIAA Paper 04-2318. 
${ }^{7}$ Taylor, H. D., “Application of Vortex Generator Mixing Principle to Diffusers. Concluding Report,” United Aircraft Corp. Research Dept., Rep. R-15064-5, East Hartford, CT, Dec. 1948.

${ }^{8}$ Grose, R. M., and Taylor, H. D., "Theoretical and Experimental Investigation of Various Types of Vortex Generators," United Aircraft Corp. Research Dept., Rep. R-15362-5, East Hartford, CT, March 1954.

${ }^{9}$ Valentine, E. F. and Carrol, R. B., "Effects of Some Arrangements of Rectangular Vortex Generators on the Static Pressure Rise Through a Short 2:1 Diffuser," NASA RM L50L04, Feb. 1951.

${ }^{10}$ Valentine, E. F. and Carrol, R. B., "Effects of Some Primary Variables of Rectangular Vortex Generators on the Static Pressure Rise Through a Short Diffuser," NASA RM L52B13, May 1952.

${ }^{11}$ Pearcy, H. H. and Stuart, C. M., "Methods of Boundary-Layer Control for Postponing and Alleviating Buffeting and other Effects of Shock-Induced Separation," Presented at the IAS National Summer Meeting, Los Angles, CA, June, 1959.

${ }^{12}$ Kaldschmidt, G., Syltedo, B. E. and Ting, C. T., "727 Airplane Center Duct Inlet Low-Speed Performance Confirmation Model Test for Refanned JT8D Engines - Phase II," NASA CR-134534, Nov. 1973.

${ }^{13}$ Anderson, B. H. and Levy, R., "A Design Strategy for the Use of Vortex Generators to Manage Inlet-Engine Distortion Using Computational Fluid Dynamics”, NASA/TM-1991-104436, June 1991.

${ }^{14}$ Hamstra, J. W., Miller, D. N., Truax, P. P., Anderson, B. H., and Wendt, B. J., "Active Inlet Flow Control Technology Demonstration," The Aeronautical Journal of the Royal Aeronautical Society, October, 2000.

${ }^{15}$ Anderson, B. H. and Keller, D. J., "Robust Design Methodologies for Optimal Micro-Scale Secondary Flow Control in Compact Inlet Diffusers", NASA/TM-2001-211477, March 2001.

${ }^{16}$ Anderson, B. H., Baust, H. D., and Agrell, J., "Management of Total Pressure Recovery, Distortion and High Cycle Fatigue in Compact Air Vehicle Inlets," NASA TM-2002-212000, December, 2002.

${ }^{17}$ Anderson, B. H. and Keller, D. J., "Optimal Micro-Scale Secondary Flow Control for the Management of HCF and Distortion in Compact Inlet Diffusers", NASA/TM-2002-211686, July 2002.

${ }^{18}$ Anderson, B. H., Baust, H. D., and Agrell, J., "Management of Total Pressure Recovery, Distortion and High Cycle Fatigue in Compact Air Vehicle Inlets,” NASA TM-2002-212000, Dec. 2002.

${ }^{19}$ Anderson, B. H. and Keller, D. J., "A Robust Design Methodology for Optimal Micro-Scale Secondary Flow Control in Compact Inlet Diffusers”, AIAA Paper No. 2002-0541, Jan. 2002.

${ }^{20}$ Anderson, B. H., Miller, D. N., Addington, G. A., and Agrell, J., "The Role of Robust Optimization in Managing Flow in Compact Air Vehicle Inlets," NASA TM-2003-212017, Jan. 2003.

${ }^{21}$ Anderson, B. H., Miller, D. N., Marvin, G. C., and Agrell, J., "The Role of Design-of-Experiments in Managing Flow in Compact Air Vehicle Inlets,” NASA TM-2003-212601, Sept. 2003.

${ }^{22}$ Anderson, B. H., Miller, D. N., Addington, G. A., and Agrell, J.," Optimal Micro-Vane Flow Control for Compact Air Vehicle Inlets," NASA TM-2004-212936, Feb. 2004.

${ }^{23}$ Anderson, B. H., Miller, D. N., Addington, G. A., and Agrell, J.," Optimal Micro-Jet Flow Control for Compact Air Vehicle Inlets," NASA TM-2004-212937, Feb. 2004.

${ }^{24}$ Anderson, B. H., Miller, D. N., Yagle, P. J., and Truax, P. P., "A Study on MEMS Flow Control For the Management of Engine Face Distortion in Compact Inlet Systems," Proceedings of the $3^{\text {rd }}$ ASME/JSME Joint Fluids Engineering Conference, July, 1999.

${ }^{25}$ Bobby L. Berrier and Melissa B. Morehouse, "Evaluation of Flush-Mounted, S-Duct Inlets With Large Amounts of Boundary Layer Ingestion," NATO/RTA Symposium on Vehicle Propulsion Integration, Warsaw, Poland, October 6-9, 2003.

${ }^{26}$ Owens L. R., Allan B. G., Gorton, S. A., "Boundary-Layer-Ingesting Inlet Flow Control," AIAA Paper 2006-0839, Jan. 2006.

${ }^{27}$ Allan, B. G., Owens L.R., "Numerical Modeling of Flow Control in a Boundary-Layer-Ingesting Offset Inlet Diffuser at Transonic Mach Numbers," AIAA Paper 2006-0845, Jan. 2006.

${ }^{28}$ Montgomery, D.C. Design and Analysis of Experiments. New York: John Wiley \& Sons.

${ }^{29}$ Buning, P. G., Jespersen, D. C., Pulliam, T. H., Klopfer, W. M., Chan, W. M., Slotnick, J. P., Krist, S. E., and Renze, K. J., “OVERFLOW User's Manual Version 1.8m," Tech. Rep., NASA Langley Research Center, 1999.

${ }^{30}$ Jespersen, D. C., Pulliam, T. H., and Buning, P. G., "Vortex Generator Modeling for Navier-Stokes Codes," AIAA 97$0644,1997$.

${ }^{31}$ Pulliam, T. H. and Chaussee, D. S., "A Diagonal Form of an Implicit Approximate-Factorization Algorithm," Journal of Computational Physics, Vol. 39, February 1981, pp. 347-363.

${ }^{32}$ Steger, J. L., Dougherty, F. C., and Benek, J. A., “A Chimera Grid Scheme,” Advances in Grid Generation, edited by K. N. Ghia and U. Ghia, Vol. 5 of FED, ASME, New York, NY, 1983.

${ }^{33}$ Menter, F., "Improved Two-Equation Turbulence Models for Aerodynamic Flows," Tech. Rep. TM 103975, NASA, NASA Langley Research Center, Hampton, VA 23681-2199, 1992.

${ }^{34}$ Allan, B. G., Yao, C. S., and Lin, J. C., "Numerical Simulations of Vortex Generator Vanes and Jets on a Flat Plate," AIAA Paper 02-3160, June 2002.

${ }^{35}$ Murphy, K., Buning, P., Pamadi, B., Scallion, W., and Jones, K., "Status of Stage Separation Tool Development for Next Generation Launch Technologies,” AIAA paper 04-2595, June 2004.

${ }^{36}$ Chan, W. M. and Gomez, R. J., "Advances in Automatic Overset Grid Generation Around Surface Discontinuities,” AIAA Paper 99-3303, July 1999.

${ }^{37}$ Gas Turbine Engine Inlet Flow Distortion Guidelines. Aerospace Recommended Practice 1420B, SAE International, 2001. 


\begin{tabular}{|c|c|}
\hline Design Factors & Range \\
\hline Bottom Vane Angle $(\mathrm{deg})$ & 10 to 20 \\
\hline Side Vane Angle $(\mathrm{deg})$ & 10 to 20 \\
\hline Bottom Vane Height $\left(\mathrm{h}_{\mathrm{B}} / \mathrm{D}_{\text {aip }}\right)$ & 0.04 to 0.1 \\
\hline Side Vane Height $\left(\mathrm{h}_{\mathrm{S}} / \mathrm{D}_{\text {aip }}\right)$ & 0.02 to 0.07 \\
\hline Fixed Variables & Value \\
\hline Free-stream Mach & 0.784 \\
\hline Reynolds Number, Re $_{\text {Daip }}$ & 13.8 million \\
\hline Inlet Mass Flow $\left(\mathrm{A}_{0} / \mathrm{A}_{\mathrm{C}}\right)$ & 0.59 \\
\hline Vane Chord Length $\left(\mathrm{c} / \mathrm{D}_{\text {aip }}\right)$ & 0.15 \\
\hline Number of Bottom Vanes & 12 \\
\hline Number of Side Vanes $($ per side) & 6 \\
\hline Response Variables & Nomenclature \\
\hline Engine Face Distortion & DC60 \\
\hline Engine Face Total Pressure Recovery & $\mathrm{PR}$ \\
\hline 1st Fourier Harmonic $1 / 2$ Amplitude & $\mathrm{F} 1 / 2$ \\
\hline 2nd Fourier Harmonic $1 / 2$ Amplitude & $\mathrm{F} 2 / 2$ \\
\hline 3rd Fourier Harmonic $1 / 2$ Amplitude & $\mathrm{F} 3 / 2$ \\
\hline 4th Fourier Harmonic $1 / 2$ Amplitude & $\mathrm{F} 4 / 2$ \\
\hline 5th Fourier Harmonic $1 / 2$ Amplitude & $\mathrm{F} 5 / 2$ \\
\hline
\end{tabular}

Table 1: First DOE design factors ranges and response variables

\begin{tabular}{|c|c|}
\hline Design Factors & Optimal Values \\
\hline Bottom Vane Angle $(\mathrm{deg})$ & 12.8 \\
\hline Side Vane Angle $(\mathrm{deg})$ & 10.0 \\
\hline Bottom Vane Height $\left(\mathrm{h}_{\mathrm{B}} / \mathrm{D}_{\text {aip }}\right)$ & 0.074 \\
\hline Side Vane Height $\left(\mathrm{h}_{\mathrm{S}} / \mathrm{D}_{\text {aip }}\right)$ & 0.065 \\
\hline
\end{tabular}

Table 2: Optimal design factors for the First DOE using a fifth order D-Optimal response surface model requiring 173 numerical simulations.

\begin{tabular}{|c|c|c|c|c|c|c|c|}
\hline Response Variable & DC60 & PR & F1/2 & F2/2 & F3/2 & F4/2 & F5/2 \\
\hline Predicted (DOE) & 0.0888 & 0.951 & 0.00908 & 0.00898 & 0.00001 & 0.00486 & 0.00700 \\
\hline Actual (CFD) & 0.0447 & 0.951 & 0.00189 & 0.00005 & 0.00088 & 0.00867 & 0.00804 \\
\hline
\end{tabular}

Table 3: Comparison of predicted response variables from the first DOE model to a CFD simulation using the optimal vane design. 


\begin{tabular}{|c|c|}
\hline Design Factor & Range \\
\hline Bottom Vane Angle $(\mathrm{deg})$ & 11 to 15 \\
\hline Side Vane Angle $(\mathrm{deg})$ & 8 to 12 \\
\hline Fixed Variable & Value \\
\hline Bottom Vane Height $\left(\mathrm{h}_{\mathrm{B}} / \mathrm{D}_{\text {aip }}\right)$ & 0.074 \\
\hline Side Vane Height $\left(\mathrm{h}_{\mathrm{S}} / \mathrm{D}_{\text {aip }}\right)$ & 0.065 \\
\hline Free-stream Mach & 0.784 \\
\hline Reynolds Number, Re $_{\text {Daip }}$ & 13.8 million \\
\hline Inlet Mass Flow $\left(\mathrm{A}_{0} / \mathrm{A}_{\mathrm{C}}\right)$ & 0.59 \\
\hline Vane Chord Length $\left(\mathrm{c} / \mathrm{D}_{\text {aip }}\right)$ & 0.15 \\
\hline Number of Bottom Vanes & 12 \\
\hline Number of Side Vanes (per side) & 6 \\
\hline Response Variable & Nomenclature \\
\hline Engine Face Distortion & $\mathrm{DC} 60$ \\
\hline Engine Face Total Pressure Recovery & $\mathrm{PR}$ \\
\hline 1st Fourier Harmonic $1 / 2$ Amplitude & $\mathrm{F} 1 / 2$ \\
\hline $2^{\text {nd }}$ Fourier Harmonic $1 / 2$ Amplitude & $\mathrm{F} 2 / 2$ \\
\hline 3rd Fourier Harmonic $1 / 2$ Amplitude & $\mathrm{F} 3 / 2$ \\
\hline 4th Fourier Harmonic $1 / 2$ Amplitude & $\mathrm{F} 4 / 2$ \\
\hline 5th Fourier Harmonic $1 / 2$ Amplitude & $\mathrm{F} 5 / 2$ \\
\hline
\end{tabular}

Table 4: Second DOE design factors ranges and response variables.

\begin{tabular}{|c|c|}
\hline Design Factor & Optimal Values \\
\hline Bottom Vane Angle $(\mathrm{deg})$ & 12.9 \\
\hline Side Vane Angle $(\mathrm{deg})$ & 11.5 \\
\hline Fixed Vane Variable & \\
\hline Bottom Vane Height $\left(\mathrm{h}_{\mathrm{B}} / \mathrm{D}_{\text {aip }}\right)$ & 0.074 \\
\hline Side Vane Height $\left(\mathrm{h}_{\mathrm{S}} / \mathrm{D}_{\text {aip }}\right)$ & 0.065 \\
\hline
\end{tabular}

Table 5. Optimal design factors for the second DOE optimization using a second order D-Optimal response surface model requiring only 15 numerical simulations.

\begin{tabular}{|c|c|c|c|c|c|c|c|}
\hline Response Variable & DC60 & PR & F1/2 & F2/2 & F3/2 & F4/2 & F5/2 \\
\hline Predicted (DOE) & 0.0377 & 0.950 & 0.00266 & 0.00410 & 0.00041 & 0.00188 & 0.00400 \\
\hline Actual (CFD) & 0.0345 & 0.950 & 0.00256 & 0.00407 & 0.00164 & 0.00073 & 0.00061 \\
\hline
\end{tabular}

Table 6: Comparison of predicted response variables for the second DOE optimization. 


\section{BLI Offset Inlet Side View}

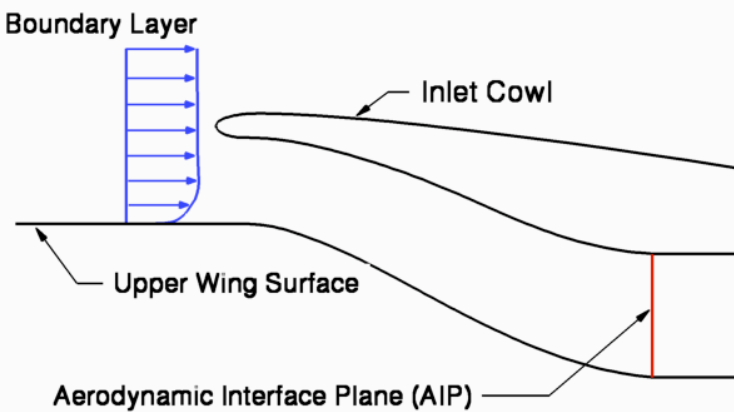

Figure 1. BLI inlet side view of the flush mounted S-shaped diffuser inlet ingesting a 30\% large boundary layer.

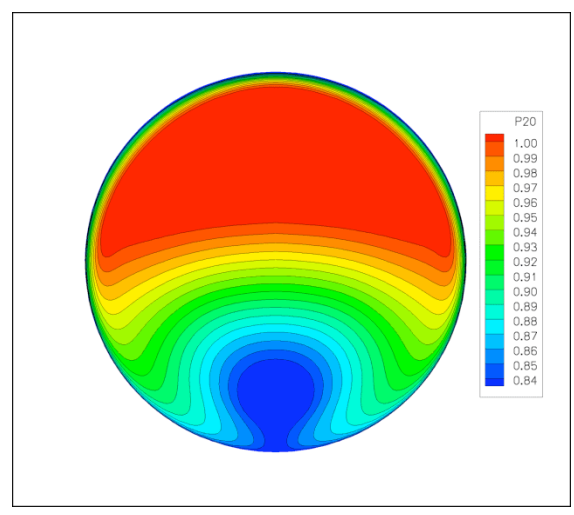

Figure 2. Contour plot of the total pressure ratio at the engine fan-face location (AIP) for the baseline numerical simulation of the BLI inlet flow. This baseline flow has a DC60 distortion of $63 \%$ and a DPCP $_{\text {avg }}$ distortion of 0.061 with pressure recovery of 0.95 .

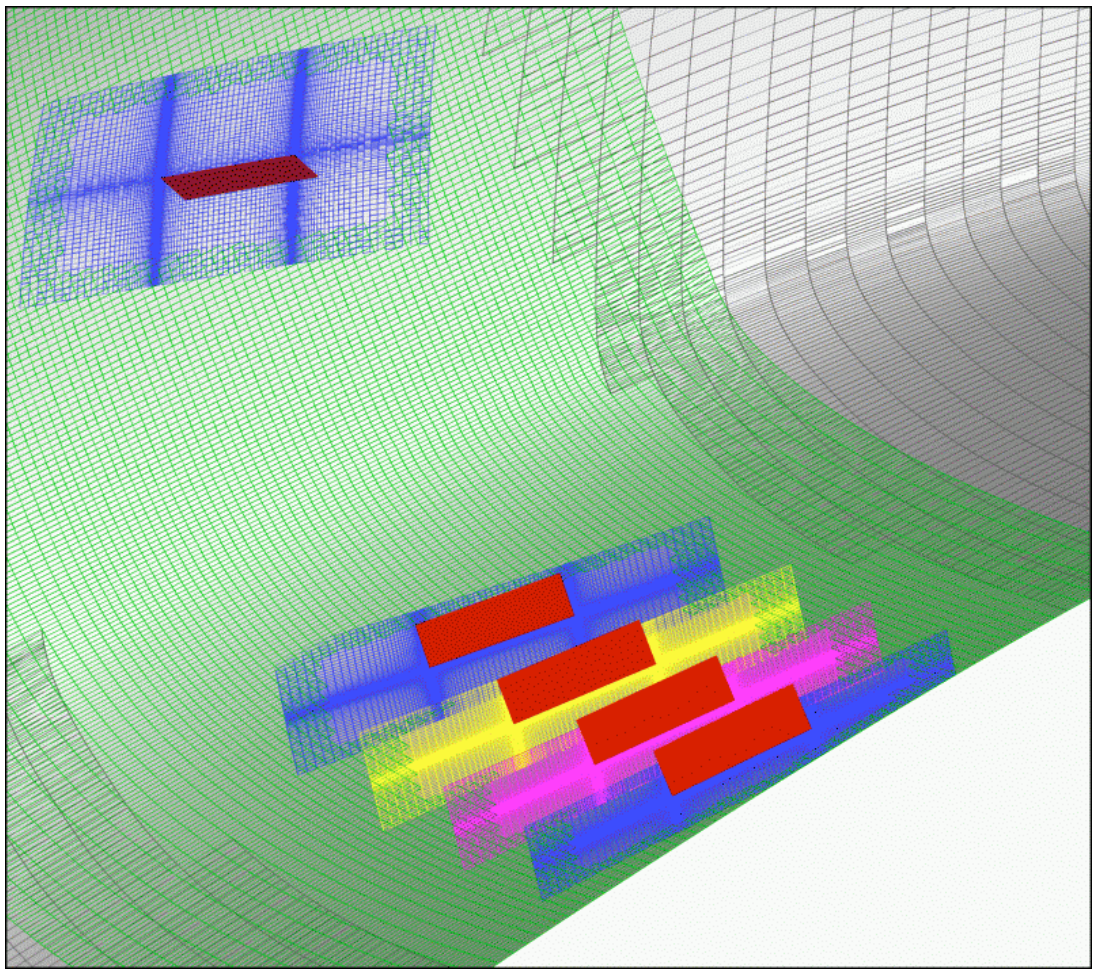

Figure 3. Overset grids for VG vanes inside the BLI inlet. 


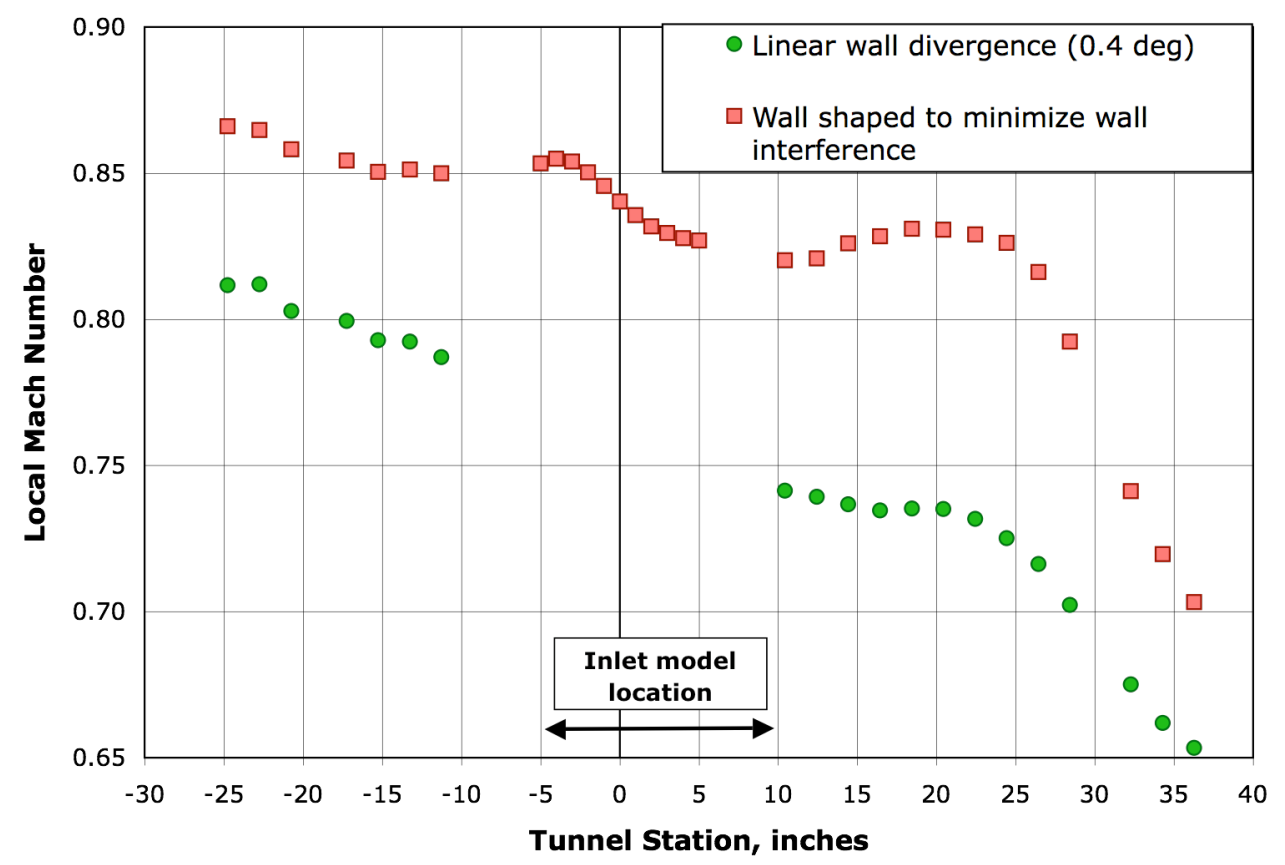

Figure 4. Local Mach number distribution computed from wall pressures measurements on the wall opposite the BLI inlet. This figure shows a comparison of the 0.3-Meter Tunnel walls set at a linear wall divergence of $0.4 \mathrm{deg}$. to a wall shape that was able to maintain a constant Mach number upstream of the inlet. Note that the inlet highlight is located at a tunnel station of -4.75 inches.
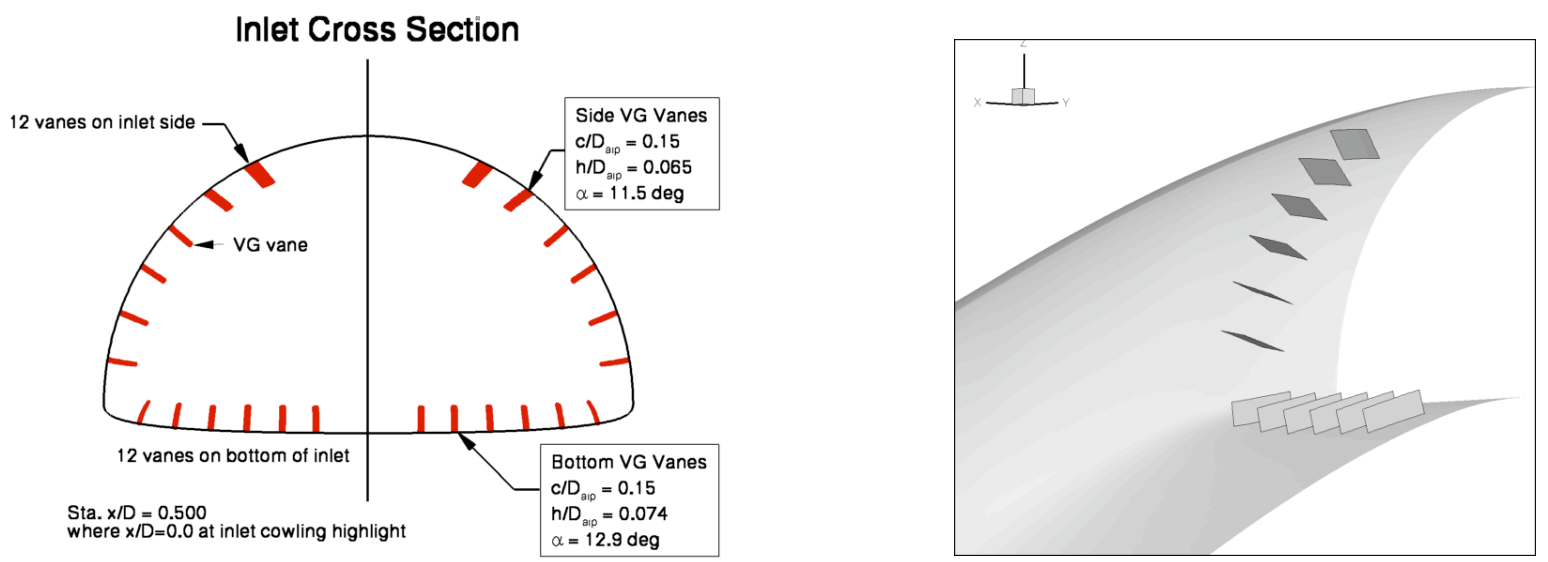

Figure 5. VG vane configuration for BLI inlet wind tunnel experiment. The cross section view shows a total of 24 vanes, which were grouped by vanes on the bottom and vanes on the sidewall of the BLI inlet. 


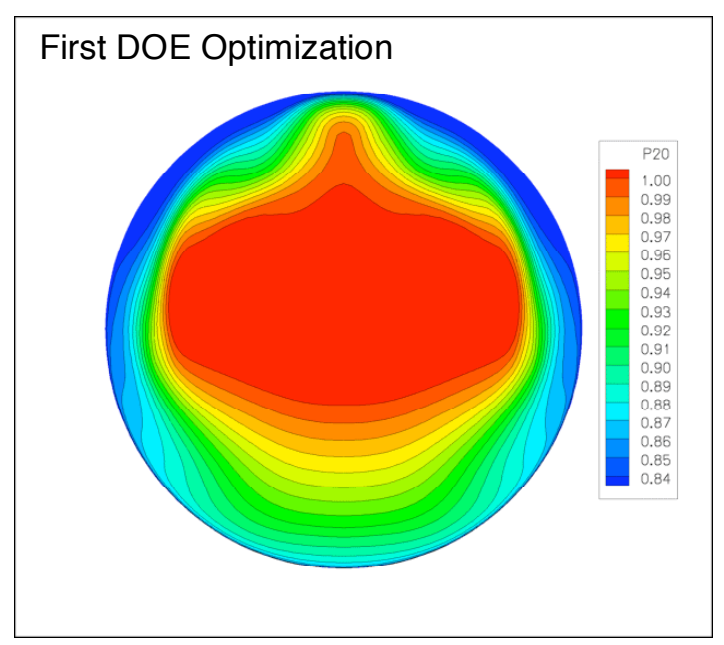

Figure 6. Contour plot of the total pressure ratio at the engine fan-face location for the first optimal VG vane design. The numerical simulation for this VG vane design had a DC60 distortion of $4.5 \%$ and a $D P C P_{\text {avg }}$ of 0.0178 with a pressure recovery of 0.95 .

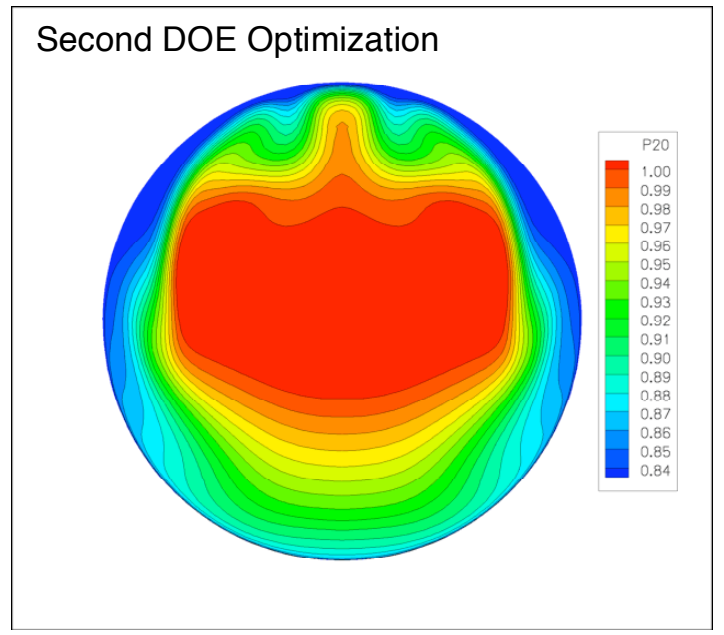

Figure 7. Contour plot of the total pressure ratio at the engine fan-face location for the second optimal VG vane design. The numerical simulation for this VG vane design had a DC60 distortion of $3.5 \%$ and a $D P C P_{\text {avg }}$ of 0.0182 with a pressure recovery of 0.95 .

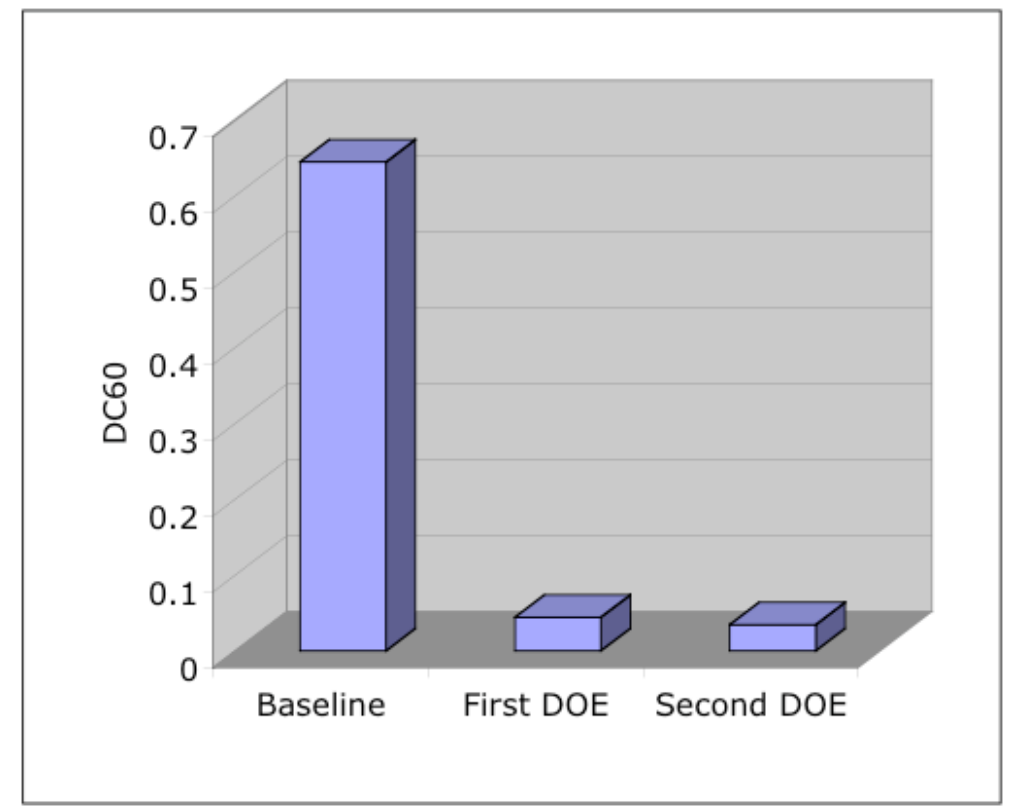

Figure 8. Summary of the DC60 engine fan-face distortion levels for the two DOE optimal vane designs and the baseline cases. 


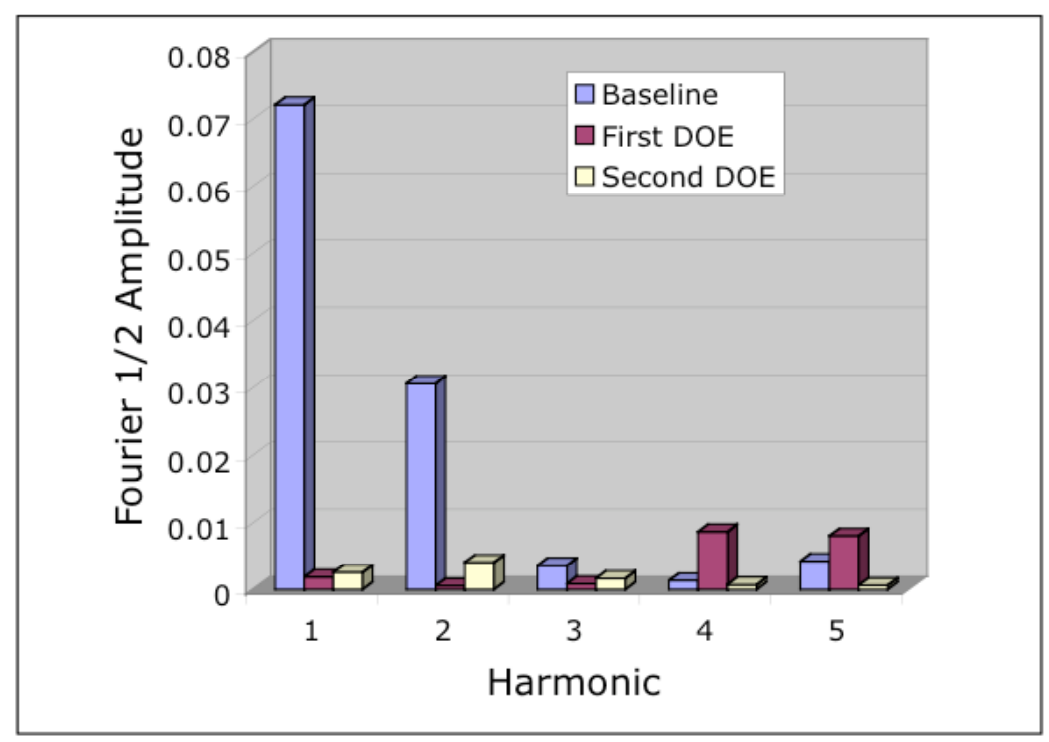

Figure 9. Summary of the first five harmonic amplitudes for the two DOE optimal vane designs with the baseline harmonic value.

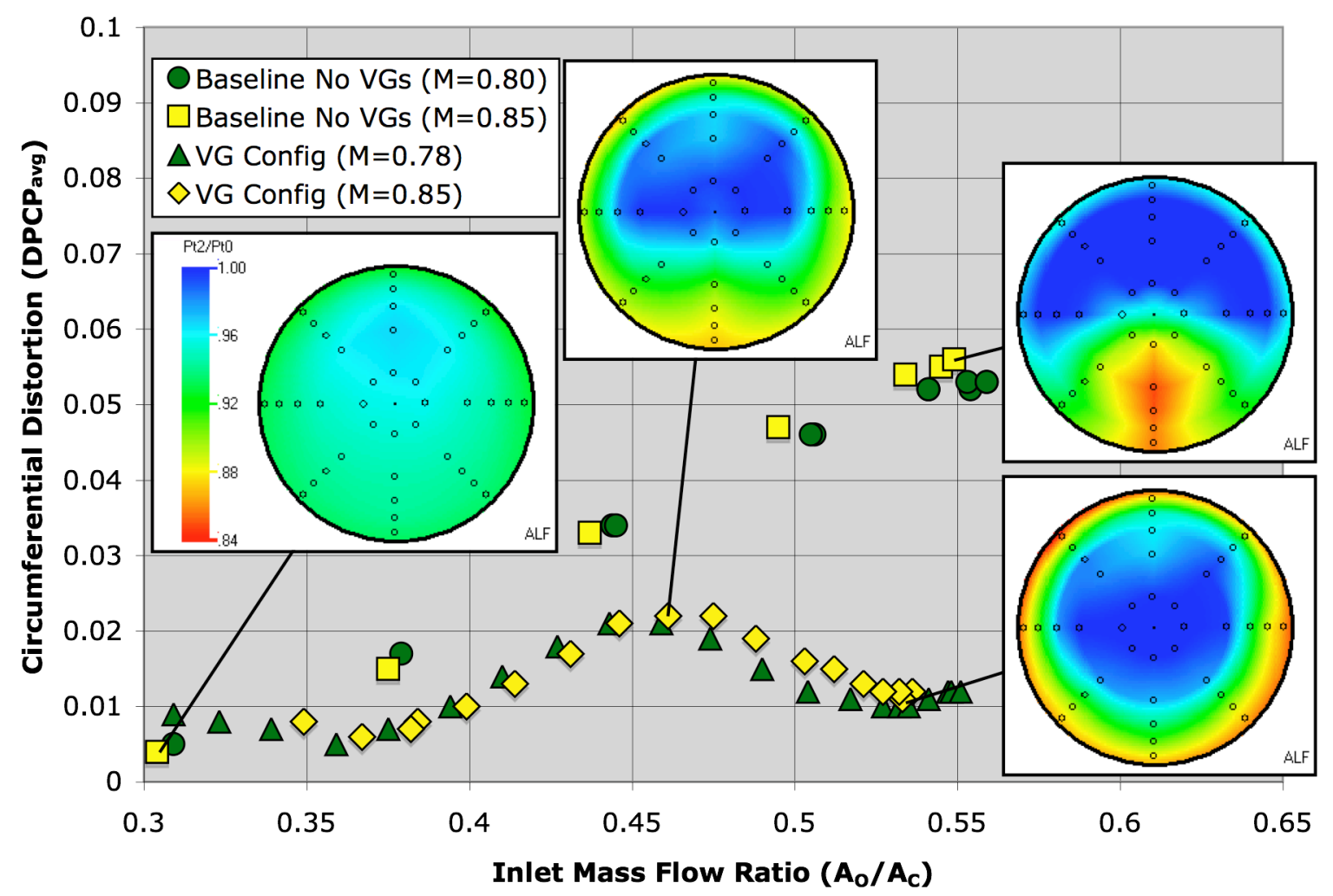

Figure 10. VG Control Effect on Distortion Reduction in BLI Inlet Experiment for $P_{t_{\infty}}=30 \mathrm{psia}, T_{t_{\infty}}=80^{\circ} \mathrm{F}$. 


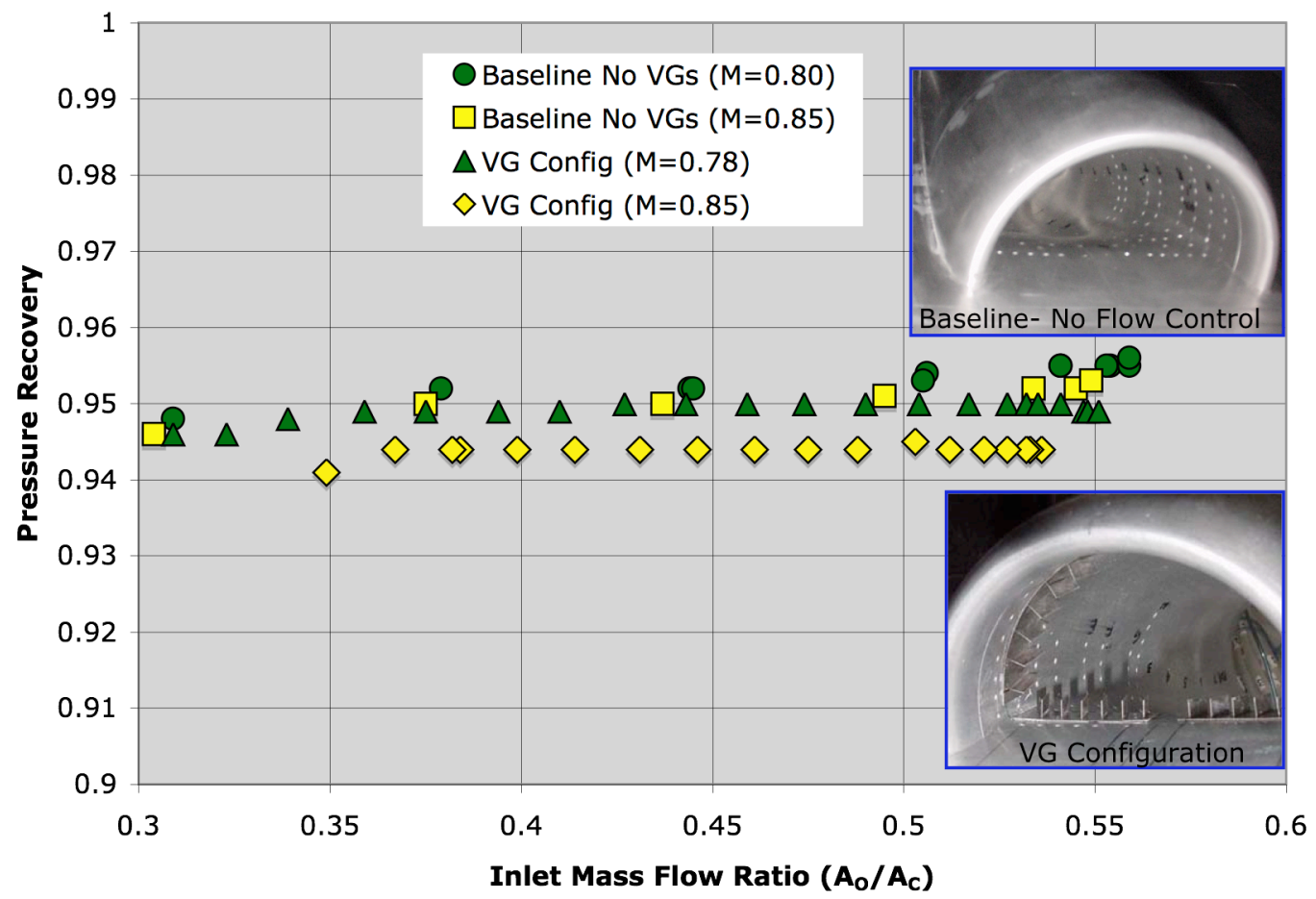

Figure 11. VG Control Effect on Pressure Recovery in BLI Inlet Experiment for $P_{t_{\infty}}=30$ psia, $T_{t_{\infty}}=80^{\circ} \mathrm{F}$.

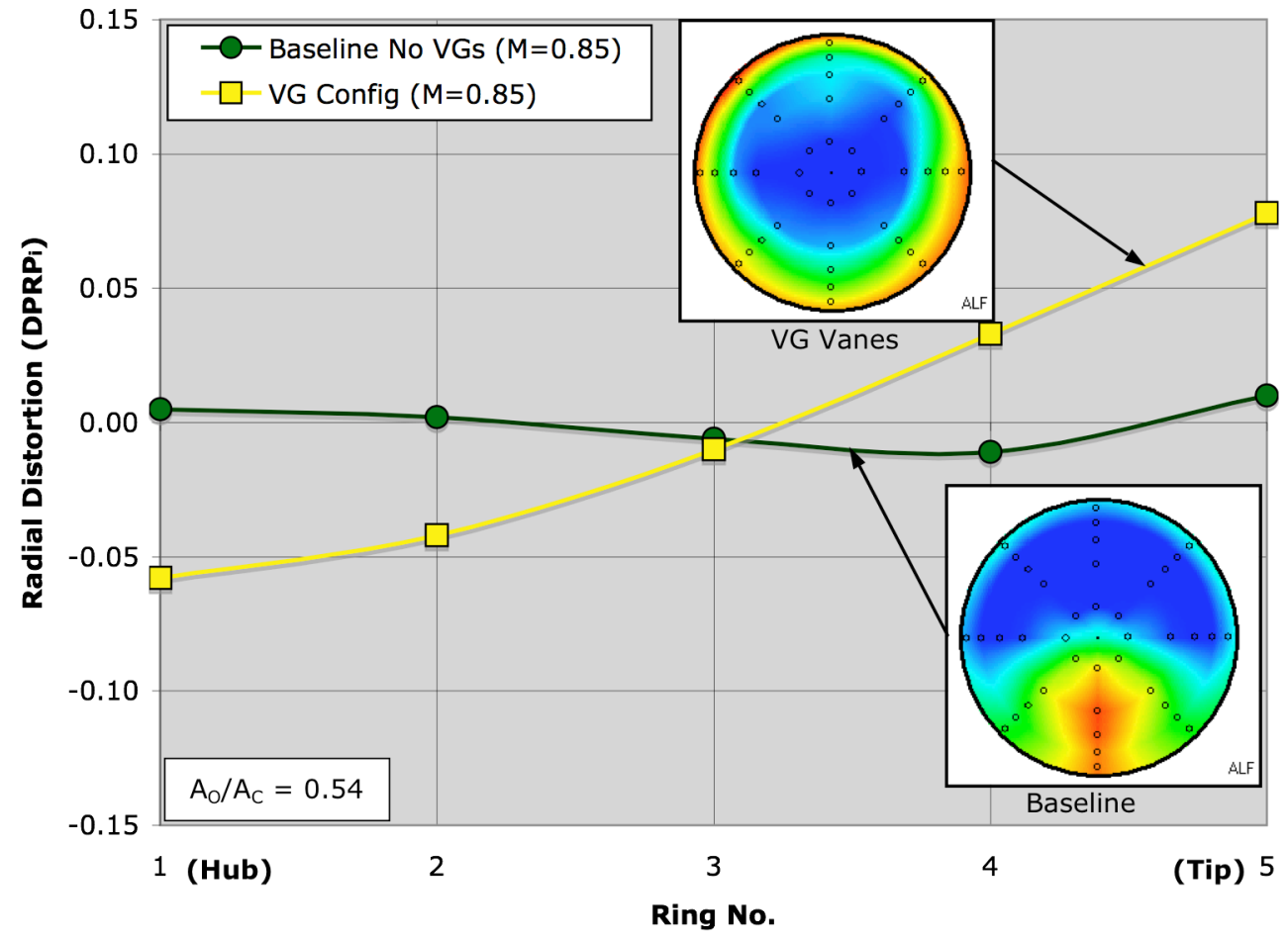

Figure 12. VG Control Effect on the Radial Distortion in the BLI Inlet Experiment $\mathbf{A}_{0} / \mathbf{A}_{\mathrm{C}}=0.54$. 